\title{
Acute optic neuritis: a prospective study of risk factors for multiple sclerosis
}

\author{
MA HELY,${ }^{*} \dagger$ PG MCMANIS, ${ }^{*} \dagger$ TJ DORAN, $\ddagger$ JC WALSH, $\dagger$ JG MCLEOD* $\dagger$ \\ From the Department of Medicine, University of Sydney, ${ }^{*}$ Department of Neurology, Royal Prince Alfred \\ Hospital, $\dagger$ and Tissue Typing Laboratory, Australian Red Cross Blood Transfusion Service, $\ddagger$ Sydney, \\ Australia.
}

SUMMARY Eighty two patients with isolated optic neuritis were studied prospectively to determine the frequency with which multiple sclerosis developed and the factors which increased its risk. Patients were followed for 6 to 264 months (mean, 57 months). Twenty six patients (32\%) developed clinically definite or probable multiple sclerosis during the period of follow-up. Actuarial analysis predicted that $42 \%$ would develop multiple sclerosis by 7 years. Of those patients who developed multiple sclerosis, $92 \%$ had symptoms within 4 years of the first attack of optic neuritis. The highest incidence of multiple sclerosis occurred in the 21-40 year age group. There was an increased risk of MS in patients with HLA-DR2 and HLA-B7 tissue types. The frequency of HLA-DR4 was increased in patients with optic neuritis alone compared to controls and to patients with multiple sclerosis, but further studies are required to confirm this finding.

The frequency with which multiple sclerosis develops following an attack of acute optic neuritis varies widely in different series and has been reported to range from $11.5 \%^{1}$ to $85 \% .^{2}$ The variability of the findings may relate to the different methods of selection of patients and diagnostic criteria, geographical factors, duration of follow-up and design of study. ${ }^{3-5}$ Risk factors have been identified in previous studies which include recurrent attacks of optic neuritis ${ }^{34}$ association with certain HLA antigen $s^{467}$ and the presence of oligoclonal bands in the cerebrospinal fluid. ${ }^{8}$ There is general agreement that there is an increased risk associated with the HLA-DW2 antigen. The aim of the present investigation was to study prospectively 82 patients who presented with acute optic neuritis and were followed for a mean interval of nearly 5 years, in order to determine the frequency with which they develop multiple sclerosis and to identify risk factors. Patients were tissue typed and were examined clinically and had visual evoked potentials (VERs) performed at the beginning and end of the study period.

Address for reprint requests: Dr JG McLeod, Department of Medicine, University of Sydney, NSW 2006, Australia.

Received 9 August 1985 and in revised form 4 January 1986. Accepted 17 January 1986

\section{Methods}

\section{Patients}

Eighty two patients with acute uncomplicated optic neuritis who had been examined and had had VERs performed in our department during the period 1975-1983 inclusive were reviewed. All patients had been referred by a neurologist or an ophthalmologist and conformed to the definition of optic neuritis as "a condition causing a relatively rapid onset of visual failure, in which no evidence for a toxic, vascular or compressive aetiology can be discovered and where local retinal lesions have been excluded". 9 In most patients the initial VER and ophthalmological examination were performed by a neurologist within 1 month of the episode of acute optic neuritis. All patients with a history or signs of demyelination outside the optic nerves at the initial examination were excluded from the study. However, patients with a prior episode of optic neuritis alone were included. Patients were subsequently reviewed neurologically and ophthalmologically, and VERs were repeated. All patients were Caucasian and $71 / 82$ had northern European ancestry.

\section{Definitions \\ A diagnosis of multiple sclerosis was based on the criteria of Rose et al.$^{10}$ Bilateral optic neuritis was defined as attacks of optic neuritis involving both eyes simultaneously or within 4 weeks of each other. Recurrent optic neuritis was defined as attacks of optic neuritis involving one or other eye at an interval greater than 4 weeks from the first attack.}

Tissue typing

HLA typing was carried out using 120 sera for HLA-A, B 
and 60 sera for HLA-DR. All sera had been standardised against cells typed on the Ninth International Workshop ${ }^{11}$ and previous workshops. For HLA-DR typing, Blymphocytes were isolated by nylon-wool separation ${ }^{12}$ followed by AET rosetting. ${ }^{13}$ Typing was carried out for HLA:-A1, A2, A3, A11, A23, A24, A25, A25, A28, (Aw68 and Aw69), A29, Aw30/31, A32, Aw33, Aw34, B5, B7, B8, B13, B14, B18, B27, B35, B37, B38, B39, B41, B45, B48, B49, B50, Bw54, Bw55, Bw56, B57, B58, B60, Bw61, Bw62, Bw63, Bw70, DR1, DR2, DR3, DR4 (DRw1 1 and DRw12), DR5, DRw6 (DRw13 and DRw14), DR7, DRw8, DRw9 and DRw10.

\section{Statistics}

Statistical comparisons of results were made using the Chisquare $\left(\chi^{2}\right)$ test. Where applicable, the Bonferroni correction for multiple comparisons was applied. The relative risk (RR) of multiple sclerosis was calculated according to the formula of Svejgaard et al. ${ }^{14} \mathrm{RR}$ is increased for values greater than 1 and is decreased for values less than 1 . To correct for the variable periods of follow-up an actuarial analysis was made to predict the probability of developing multiple sclerosis. ${ }^{15}$

\section{Initial examination}

Eighty two patients (59 females (72\%) and 23 males $(28 \%))$ presented with acute optic neuritis. Their ages ranged from 10 to 50 years (mean 29.2). VERs were abnormal in 97 of 103 affected eyes.

\section{Follow-up examination}

Twenty six of the 82 patients $(32 \%)$ progressed to clinically definite (22) or probable (4) multiple sclerosis (ON-MS) during the follow-up period of 7 to 144 months (mean 57 months; median 47 months). The remaining 56 patients with optic neuritis only (ON) were followed for 6 to 264 months, (mean 57 months; median 55 months). When life table analysis was used it was predicted that $42 \%$ would have progressed to multiple sclerosis by 7 years (fig).

There was no significant difference in the rate of progression to multiple sclerosis for males and females $\left(\chi^{2}=3.0 ; p>0.5\right)$ but the relative risk for females was increased $(R R=2 \cdot 8)$. There was no significant difference in the mean ages of the ON (mean 29.4 years) and the ON-MS groups (mean 28.8 years). Twenty two of the 26 patients $(85 \%)$ who progressed to multiple sclerosis were aged 21 to 40 years while $66 \%$ of the total patients studied were in this group. There is a significantly greater risk of developing multiple sclerosis for patients in the 21 to 40 year age group than those outside this age range $\left(\chi^{2}=6.0 ; p\right.$ $<0.05$ ) (table 1). The interval between the initial episode of optic neuritis and the first manifestation of symptoms of demyelination outside the optic nerves ranged from one month to 7 years (mean 21 months; median 14 months). Sixteen of 26 patients (61.5\%) had developed symptoms of multiple sclerosis by 24 months and $24 / 26(92 \%)$ by 48 months.
Recurrent and bilateral optic neuritis

Twenty seven patients had recurrent attacks of optic neuritis in one or other eye prior to the onset of nonoptic nerve symptoms. Recurrent attacks occurred in $18 / 56(32 \%)$ patients in the ON group and 9/26 patients $(35 \%)$ in the ON/MS group. The difference is not significant $(p>0.05)$ and the relative risk of multiple sclerosis for those with recurrent optic neuritis is only $1 \cdot 1$. Bilateral optic neuritis occurred in nine patients, four of whom developed multiple sclerosis (44\%); the relative risk of developing multiple sclerosis was increased $(R R=1.9)$ but the difference was not significant $(p>0.05)$.

\section{Tissue typing}

The results of tissue typing are shown on table 2. The control group, obtained from the Sydney Red Cross Blood Transfusion Service, consisted of 552 people analysed for HLA-A and -B alleles and 225 people analysed for HLA-DR alleles. There was no significant difference between the ON, ON-MS and control groups for frequency of HLA-A3. The frequency of HLA-B7 was similar in the ON group to the control population but HLA-B7 was significantly increased in the group who developed multiple sclerosis when compared to controls $\left(\chi^{2}=11.3 ; \mathrm{p}<0.001\right)$. HLA-DR2 was significantly increased in frequency in the ON-MS group when compared to controls, $\left(\chi^{2}=\right.$ 18.5; $\mathrm{p}<0.001$ ) and to a lesser degree in ON compared to controls $\left(\chi^{2}=5.8, p<0.05\right)$. In an attempt to assess whether the frequency of HLA-DR2 was increased in the ON group because some of the patients may subsequently develop multiple sclerosis, the $32 \mathrm{ON}$ patients who had been followed for greater than 4 years (range 54-264 months, mean 86 months) were compared with the control population: the frequency of HLA-DR2 remained significantly elevated $\left(\chi^{2}=12 ; \mathrm{p}<0.001\right)$, and was not significantly different from ON-MS patients $\left(\chi^{2}=0 \cdot 3\right)$. A combination of HLA-B7/DR2 occurred more frequently in the ON/MS group than in those with ON alone $\left(\chi^{2}=\right.$ $8.9 ; \mathrm{p}<0.01$ ).

The relative risk of multiple sclerosis in patients with different tissue types was HLA-A3 $(R R=1 \cdot 6)$, HLA-B7 $(\mathrm{RR}=4 \cdot 7)$, HLA-DR2 $(\mathrm{RR}=2.7)$ and HLA-B7/DR2 (RR = 4.8). HLA-DR4 was present in $24 / 53(45 \%)$ patients with $\mathrm{ON}$ and in $4 / 26(15 \%)$ patients with ON-MS. The difference between ON

Table 1 Age at onset of optic neuritis

\begin{tabular}{llc}
\hline Age (years) & $\begin{array}{l}O N \\
(n=56)\end{array}$ & $\begin{array}{l}O N-M S \\
(n=26)\end{array}$ \\
\hline$<20$ & 13 & 2 \\
$21-30$ & 15 & 14 \\
$31-40$ & 17 & 8 \\
$41-50$ & 11 & 2 \\
\hline
\end{tabular}


Table 2 Tissue typing results

\begin{tabular}{|c|c|c|c|c|c|}
\hline \multirow{2}{*}{$\frac{\text { Antigen }}{\text { Total no }}$} & \multicolumn{2}{|c|}{ No positive } & \multicolumn{3}{|c|}{ Antigen frequency } \\
\hline & $\begin{array}{l}\text { ON } \\
53\end{array}$ & $\begin{array}{l}O N-M S \\
26\end{array}$ & $O N$ & $O N-M S$ & $\begin{array}{l}\text { Controls } \\
522\end{array}$ \\
\hline $\begin{array}{c}\text { A-Locus } \\
\text { A1 } \\
\text { A2 } \\
\text { A3 } \\
\text { A11 } \\
\text { A23 } \\
\text { A24 } \\
\text { A25 } \\
\text { A26 } \\
\text { A28 } \\
\text { A29 } \\
\text { Aw30/31 } \\
\text { A32 } \\
\text { Aw33 }\end{array}$ & $\begin{array}{r}15 \\
28 \\
13 \\
6 \\
1 \\
11 \\
1 \\
7 \\
4 \\
0 \\
2 \\
4 \\
0\end{array}$ & $\begin{array}{r}10 \\
7 \\
9 \\
0 \\
0 \\
1 \\
4 \\
1 \\
2 \\
0 \\
3 \\
1 \\
0\end{array}$ & $\begin{array}{l}0.283 \\
0.528 \\
0.245 \\
0.113 \\
0.019 \\
0.208 \\
0.019 \\
0.132 \\
0.075 \\
0 \\
0.038 \\
0.075 \\
0\end{array}$ & $\begin{array}{l}0.385 \\
0.269 \\
0.346 \\
0 \\
0 \\
0.038 \\
0.154 \\
0.038 \\
0.077 \\
0 \\
0.115 \\
0.038 \\
0\end{array}$ & $\begin{array}{l}0.351 \\
0.489 \\
0.259 \\
0.128 \\
0.017 \\
0.167 \\
0.044 \\
0.165 \\
0.052 \\
0.094 \\
0.067 \\
0.073 \\
0.002\end{array}$ \\
\hline $\begin{array}{l}\text { B-Locus } \\
\text { B5 } \\
\text { B7 } \\
\text { B8 } \\
\text { B13 } \\
\text { B14 } \\
\text { B17 } \\
\text { B18 } \\
\text { B27 } \\
\text { B35 } \\
\text { B37 } \\
\text { B38 } \\
\text { B39 } \\
\text { B41 } \\
\text { B44 } \\
\text { B45 } \\
\text { B48 } \\
\text { B49 } \\
\text { B50 } \\
\text { Bw53 } \\
\text { Bw54 } \\
\text { Bw55 } \\
\text { Bw56 } \\
\text { B57 } \\
\text { B58 } \\
\text { B60 } \\
\text { Bw61 } \\
\text { Bw62 } \\
\text { Bw63 } \\
\text { Bw70 } \\
\text { DR-Locus } \\
\text { DR1 } \\
\text { DR2 } \\
\text { DR3 } \\
\text { DR4 } \\
\text { DR5 } \\
\text { DRw6 } \\
\text { DR7 } \\
\text { DRw8 } \\
\text { DRw9 } \\
\text { DRw10 } \\
\text { B7/DR2 } \\
\text { A3/B7/DR2 }\end{array}$ & $\begin{array}{r}53 \\
10 \\
12 \\
12 \\
0 \\
5 \\
1 \\
3 \\
5 \\
8 \\
2 \\
1 \\
2 \\
1 \\
13 \\
1 \\
0 \\
4 \\
1 \\
1 \\
0 \\
1 \\
3 \\
2 \\
2 \\
5 \\
3 \\
3 \\
0 \\
0 \\
53 \\
10 \\
22 \\
14 \\
24 \\
7 \\
11 \\
8 \\
0 \\
0 \\
0 \\
8 \\
3\end{array}$ & $\begin{array}{r}26 \\
0 \\
15 \\
11 \\
1 \\
0 \\
0 \\
0 \\
3 \\
6 \\
0 \\
0 \\
0 \\
0 \\
4 \\
0 \\
0 \\
0 \\
0 \\
0 \\
0 \\
0 \\
0 \\
0 \\
1 \\
1 \\
1 \\
0 \\
0 \\
0 \\
26 \\
4 \\
17 \\
10 \\
4 \\
2 \\
2 \\
5 \\
0 \\
0 \\
0 \\
12 \\
5\end{array}$ & $\begin{array}{l}0.189 \\
0.226 \\
0.226 \\
0 \\
0.094 \\
0.019 \\
0.057 \\
0.094 \\
0.151 \\
0.038 \\
0.019 \\
0.038 \\
0.019 \\
0.245 \\
0.019 \\
0 \\
0.075 \\
0.019 \\
0.019 \\
0 \\
0.019 \\
0.057 \\
0.038 \\
0.038 \\
0.094 \\
0.057 \\
0.057 \\
0 \\
0 \\
0.189 \\
0.415 \\
0.264 \\
0.453 \\
0.132 \\
0.208 \\
0.151 \\
0 \\
0 \\
0 \\
0.151 \\
0.057\end{array}$ & $\begin{array}{l}0 \\
0 \cdot 577 \\
0 \cdot 423 \\
0 \cdot 038 \\
0 \\
0 \\
0 \\
0 \cdot 115 \\
0 \cdot 231 \\
0 \\
0 \\
0 \\
0 \\
0 \cdot 154 \\
0 \\
0 \\
0 \\
0 \\
0 \\
0 \\
0 \\
0 \\
0 \\
0 \cdot 038 \\
0 \cdot 038 \\
0 \cdot 038 \\
0 \\
0 \\
0 \\
0 \cdot 154 \\
0 \cdot 654 \\
0 \cdot 385 \\
0 \cdot 154 \\
0 \cdot 077 \\
0 \cdot 077 \\
0 \cdot 192 \\
0 \\
0 \\
0 \\
0 \cdot 462 \\
0 \cdot 192\end{array}$ & $\begin{array}{l}522 \\
0.100 \\
0.272 \\
0.266 \\
0.042 \\
0.075 \\
0.098 \\
0.094 \\
0.096 \\
0.130 \\
0.010 \\
0.034 \\
0.033 \\
0.015 \\
0.264 \\
0.002 \\
0.004 \\
0.013 \\
0.013\end{array}$ \\
\hline
\end{tabular}

and controls $\left(\chi^{2}=5.3 ; p<0.05\right)$ and $\mathrm{ON}$ and $\mathrm{ON}$ MS groups $\left(\chi^{2}=6.8 ; p<0.01\right)$ did not reach levels of significance after application of the correction factor for multiple comparisons. The relative risk of multiple sclerosis in patients with HLA-DR4 was one fifth that of patients without HLA-DR4.
Actuarial analysis predicts that of all patients presenting with acute optic neuritis, $42 \%$ develop multiple sclerosis in 7 years. A greater proportion of patients who are HLA-DR2 positive $(61 \%)$ develop multiple sclerosis, than those who are HLA-DR2 negative $(30 \%)$ or HLA/DR4 positive $(26 \%)(\mathrm{fig})$. 


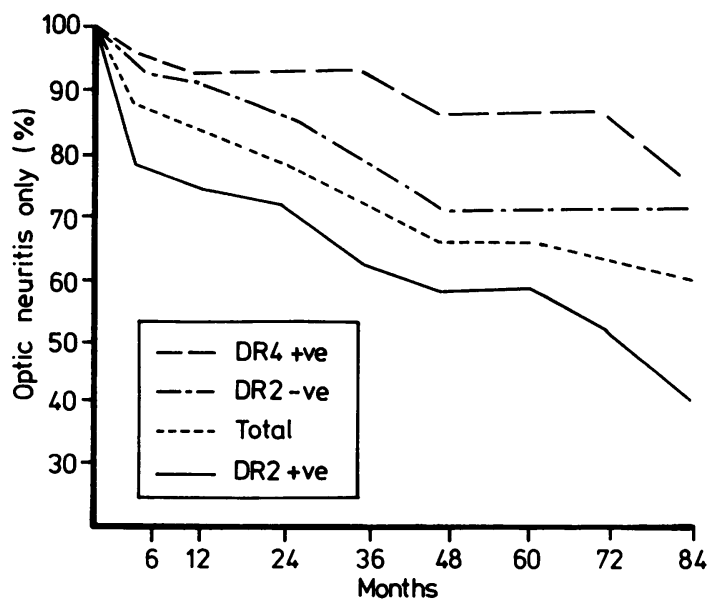

Fig Actuarial curves showing the percentage of patients who have not developed multiple sclerosis at each interval of follow-up.

Numbers studied at each interval:

Months $\quad 0-6 \quad 7-12 \quad 13-24$ 25-36 37-48 48-60 61-72 73-84

Total

DR2 + ve

DR2 - ve

$\begin{array}{ccc}0-6 & 7-12 & 13-24 \\ 82 & 70 & 60\end{array}$

DR4 + ve

$\begin{array}{lll}82 & 70 & 60 \\ 38 & 30 & 26 \\ 40 & 36 & 31 \\ 28 & 27 & \end{array}$

$28 \quad 27$

49
22
24
18

$\begin{array}{ll}37 & 34 \\ 17 & 15 \\ 18 & 16 \\ 14 & 12\end{array}$

$\begin{array}{rrr}34 & 23 & 17 \\ 15 & 9 & 5 \\ 16 & 13 & 11 \\ 12 & 10 & 8\end{array}$

\section{Combination of risk factors}

Female sex, age $21-40$, presence of HLA-DR2 or HLA-B7 tissue types add to the cumulative risk while HLA-DR4 decreases the risk regardless of sex. There is a slightly increased risk in patients with bilateral optic neuritis.

\section{Discussion}

There have been a number of previous studies of optic neuritis progressing to multiple sclerosis ${ }^{1216-20}$ in some of which ${ }^{2122}$ patients who had symptoms of demyelination in the central nervous system prior to the onset of the optic neuritis have not been excluded. In the present study patients with symptoms or signs of demyelination elsewhere in the central nervous system that preceded or were concurrent with optic neuritis were excluded.

The diagnostic criteria for clinically definite or probable multiple sclerosis were satisfied in $32 \%$ of patients after a mean follow-up of 57 months. Lifetable analysis predicted that $42 \%$ of patients with optic neuritis would develop multiple sclerosis within 7 years. McDonald ${ }^{5}$ has suggested that geographical factors may be important in accounting for the variation in frequency of developing multiple sclerosis in the different reported studies. Another prospective study from tropical and subtropical areas of Australia has reported a risk of $56 \%,{ }^{23}$ which is comparable to that of $50-60 \%$ in the United Kingdom. ${ }^{4917}$ A somewhat lower incidence, similar to our own, of $30-40 \%$ has been reported from the United States. $^{31621}$ The unusually low frequency of $13 \%$ reported by Kurland et $a l^{1}$ may be due to the fact that their study was confined to male patients. A recent study from Finland ${ }^{22}$ established that $19 \%$ of patients with optic neuritis develop multiple sclerosis during a follow-up period of 5 years; lifetable analysis predicted that the probability of developing multiple sclerosis was $38 \%$ and $24 \%$ in 2 different provinces after 9 years. It does not appear from these studies that there is any clear association with latitude.

In the present study $92 \%$ of patients who developed multiple sclerosis had developed symptoms outside the optic nerves within 4 years. All of the patients who developed multiple sclerosis in the studies of Collis ${ }^{16}$ and Percy et $\mathrm{l}^{18}$ had done so by 4 years despite prolonged follow-up periods of 7-20 years and 2-33 years respectively. Bradley and Whitty ${ }^{17}$ stated that definite multiple sclerosis usually developed within the first 4 years and Landy et al $^{23}$ found that most of their cases who subsequently developed multiple sclerosis did so within 2 years of the onset of optic neuritis. Nevertheless it is clear that the longer patients are followed, the higher will be the incidence of multiple sclerosis. 520

Females presenting with optic neuritis outnumbered males in the present study, a finding consistent with other reports ${ }^{1723-25}$ There was a greater relative risk of progression to multiple sclerosis in females which is consistent with the observations of some workers ${ }^{31625}$ but not those of others. ${ }^{91723}$ The largest number of patients with optic neuritis were in the 21-40 year age group and they had a significantly greater risk of developing multiple sclerosis. The finding that patients in the younger adult age groups are more likely to develop multiple sclerosis is consistent with the reports of other workers. ${ }^{31626}$ By contrast, Bradley and Whitty ${ }^{17}$ found the likelihood of developing multiple sclerosis greater in older age patients.

In the present study there was no statistically significant increase in the frequency of multiple sclerosis in patients with bilateral or recurrent optic neuritis, although the relative risk was increased in the former group. Parkin et al $^{27}$ found a very low risk of developing multiple sclerosis after simultaneous bilateral or recurrent optic neuritis in childhood and a relatively low risk in adults. Kinnunen ${ }^{25}$ also found that recurrent optic neuritis did not increase the risk of multiple sclerosis. However, recurrent attacks of optic neuritis were a significant risk factor in the studies of Compston et $^{4} \mathrm{l}^{4}$ and Cohen et al. ${ }^{3}$ The frequencies of 
HLA-A3 and -B7 antigens in ON patients did not differ significantly from the control population but HLA-B7 was signficantly increased in the ON-MS group, a finding noted by other workers. ${ }^{28}$ HLA-DR2 was significantly more frequent in ON-MS patients than in controls. It was also significantly elevated but to a lesser extent in the $\mathrm{ON}$ group. These findings are similar to those of others. ${ }^{48}$ The finding of Sandberg-Wollheim et al ${ }^{7}$ that all three histocompatibility antigens occurred at similar frequencies in $\mathrm{ON}$ and multiple sclerosis may be explained by their short follow-up period of 2.6 years. In our study there was a greater risk of developing multiple sclerosis if the HLA-B7 antigen was present in combination with HLA-DR2 than with HLA-DR2 alone. It is possible that HLA-DR2 is associated closely to a gene or genes that increase susceptibility not only to multiple sclerosis but also to optic neuritis that does not progress, and that other genetic and environmental factors lead to the development of chronic, recurrent demyelination.

It is of interest that in our study the frequency of HLA-DR4 is increased in patients with optic neuritis alone compared to controls and to ON-MS patients. It is thus possible that HLA-DR4 is not in linkage disequilibrium with the multiple sclerosis susceptibility gene(s) in this population of predominantly northern European extraction, although it is in Jordanian Arabs. ${ }^{29}$ For this reason, the presence of DR4 may offer a reduced risk of disseminated demyelination, although the risk of optic neuritis in isolation appears to be increased. Further studies are required to verify this finding.

A close relationship between isolated optic neuritis and multiple sclerosis is apparent but the different HLA frequencies in the two groups suggest that different immunological factors may be active in allowing only some patients to progress to multiple sclerosis. In the present study female sex, young adult age and the presence of HLA-B7 or -DR2 increased the risk of developing multiple sclerosis and, in another study, the presence of oligoclonal bands. ${ }^{8}$ However, none of these features is a reliable guide to prognosis in individual patients.

\section{References}

\footnotetext{
${ }^{1}$ Kurland LT, Auth TL, Beebe GW, et al. Studies on the natural history of multiple sclerosis II. Progression from optic neuropathy to multiple sclerosis. Trans Am Neurol Assoc 1963;88:233-5.

${ }^{2}$ Lynn BH. Retrobulbar neuritis. A survey of the present condition of cases occurring over the last fifty-six years. Trans Ophthalmol Soc UK 1959;79:701-16.

${ }^{3}$ Cohen MM, Lessell S, Wolf PA. A prospective study of the risk of developing multiple sclerosis in uncomplicated optic neuritis. Neurology 1979;29:208-13.
}

${ }^{4}$ Compston DAS, Batchelor JR, Earl CJ, McDonald WI. Factors influencing the risk of multiple sclerosis developing in patients with optic neuritis. Brain 1978;101:495-511.

${ }^{5}$ McDonald WI, Multiple sclerosis: the present position. Acta Neurol Scand 1983;68:65-76.

${ }^{6}$ Arnason BGW, Fuller TC, Lehrich FR, Wray SH. Histocompatibility types and measles antibodies in multiple sclerosis and optic neuritis. $J$ Neurol Sci 1974;22:419-28.

${ }^{7}$ Sandberg-Wollheim M, Platz P, Ryder LP, Staub Nielsen L, Thomsen M. HLA-Histocompatibility antigens in optic neuritis. Acta Neurol Scand 1975;52:161-6.

${ }^{8}$ Moulin D, Paty DW, Ebers GC. The predictive value of cerebrospinal fluid electrophoresis in 'possible' multiple sclerosis. Brain 1983;106:809-16.

${ }^{9}$ Perkin GD, Rose FC. Optic Neuritis and its Differential Diagnosis. Oxford: Oxford University Press, 1979:19.

${ }^{10}$ Rose A, Ellison G, Myers LW, Tourtellotte WW. Criteria for the clinical diagnosis of multiple sclerosis. Neurology 1976;26 (suppl):20-22.

${ }^{11}$ Alberti I, Ord Meyer W, eds. Histocompatibility Testing Copenhagen. Muuskaara 1984.

${ }^{12}$ Danilovs JA, Ayoub C, Terasaki PJ. B-lymphocyte isolation by thrombin-nylon wool. In: Terasaki PJ, ed. Histocompatibility Testing 1980;UCLA:287.

${ }^{13}$ Rood JJ, van Leevwen A, van Keuning JJ, van Oud Ablas AB. The serological recognition of the human MLC determinants using a modified cytotoxicity technique. Tissue Antigens 1975;5:73-9.

${ }^{14}$ Svejgaard A, Hauge M, Jersild C, Platz P, Ryder LP, Staub Nielson L, Thomsen M. The HLA system. An introductory survey. In: Beckman L, Hauge $\mathbf{M}$, eds. Monographs in Human Genetics. Vol.7, Basel: Karger, 1975:1-103.

${ }^{15}$ Barnes BA. Survival data of renal transplantations in patients. Transplantation 1965;3:812-21.

${ }^{16}$ Collis WJ. Acute unilateral retrobulbar neuritis. Arch Neurol 1965;13:409-12.

${ }^{17}$ Bradley WG, Whitty CWM. Acute optic neuritis: prognosis for development of multiple sclerosis. J Neurol Neurosurg Psychiatry 1968;31:10-18.

${ }^{18}$ Percy AK, Norbrega FT, Kurland LT. Optic neuritis and multiple sclerosis. Arch Ophthalmol 1972;87:135-9.

${ }^{19}$ Hutchinson WM. Acute optic neuritis and the prognosis for multiple sclerosis. J Neurol Neurosurg Psychiatry 1976;39:283-9.

${ }^{20}$ Ebers GC, Cousin HK, Feasbý TE, Paty DW. Optic neuritis and familial multiple sclerosis. Neurology 1981;31:1138-42.

${ }^{21}$ Hyllested K, Moller PM. Follow-up on patients with a history of optic neuritis. Act Ophthalmol 1961;39:655-62.

${ }^{22}$ Nikoskelainen E, Riekkinen P. Optic neuritis-A sign of multiple sclerosis or other diseases of the central nervous system. A retrospective analysis of 116 patients. Acta Neurol Scand 1974;50:690-718.

${ }^{23}$ Landy PJ. A prospective study of the risk of developing multiple sclerosis in optic neuritis in a tropical and subtropical area. Journal of Neurology, Neurosurgery and Psychiatry 1983;46:659-61.

${ }^{24}$ Sandberg HO. Acute retrobulbar neuritis: a retrospective 
study. Acta Ophthalmol 1972;50:3-8.

${ }^{25} \mathrm{Kinnunen} \mathrm{E}$. The incidence of optic neuritis and its prognosis for multiple sclerosis. Acta Neurol Scand 1983;68:371-7.

${ }^{26}$ Taub RG, Rucker TW. The relationship of retrobulbar neuritis to multiple sclerosis. Am J Ophthalmol 1954;37:494-7.

${ }^{27}$ Parkin PJ, Hierons R, McDonald WI. Bilateral optic neu- ritis: a long-term follow-up. Brain 1984;107:951-64.

${ }^{28}$ Stendahl-Brodin L, Link H, Moller E, Norrby E. Optic neuritis and distribution of genetic markers of the HLA system. Acta Neurol Scand 1978;57:418-31.

${ }^{29}$ Kurdi A, Ayesh J, Abdallat A, et al. Different Blymphocyte alloantigens associated with multiple sclerosis in Arabs and North Europeans. Lancet 1977;1:1123-5. 